\title{
Situational Reconstruction of C Programming Technology based on the Systematic Work Process for polytechnic
}

\author{
Wuxue Jiang ${ }^{1, \mathrm{a}}$, Jingjing $\mathrm{Bao}^{2, \mathrm{~b}}$, Libin $\mathrm{Gao}^{3, \mathrm{c}}$, Shufei $\mathrm{Li}^{1, \mathrm{~d}}$ \\ ${ }^{1}$ Department of Computer Engineering, Dongguan Polytechnic, Dongguan 523808, Guangdong, China \\ ${ }^{2}$ Department of Electronic Engineering, Dongguan Polytechnic, Dongguan 523808, Guangdong, China \\ ${ }^{3}$ Department of Computer Science, Qiannan Polytechnic for nationalities, Duyun 558022, Guizhou, \\ China

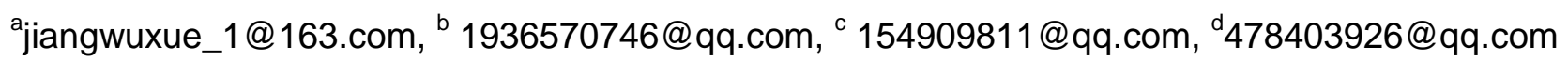

Keywords: Systematic work process, Learning environment, C Programming, Curriculum reconstruction, Massive open online courses (MOOCs)

\begin{abstract}
In order to further improve more efficient application of the $\mathrm{C}$ programming technology in IT industry and promote the scope of application of $\mathrm{C}$ programming technology in professional positions, by making use of the work process systematic theory, with "C Language" database as a carrier and in close connection with the current demand of positions of IT companies for programming technology, the author proposed the idea to reconstruct $\mathrm{C}$ programming technology system and built the development process based on vocational learning environment, including six aspects of identification of typical tasks, induction of fields of action, transformation of learning areas, development of curriculum system and personnel training programs, design of teaching situation in learning areas and planning curriculum standards, action-oriented teaching implementation and teaching evaluation and feedback. The system can effectively provide the training basis for vocational education, but also provide a strong guarantee for technical personnel needs in the IT enterprise database.
\end{abstract}

\section{Introduction}

In the 1990s, Professor Felix Rauner in the University of Bremen in Germany proposed vocational education programs concepts and methods based on the work processes, setting off a wave of curriculum reform in order to train professional competence. Working process systematization curriculum reform has become a hot point for vocational education related people to care and study.

With further promotion of the reform of vocational education, vocational curriculum reform experienced two stages of "transition from the traditional curriculum discipline system to improved disciplinary courses system with strengthened practice" and "vocation adaptability training directed curriculum reform". At present, it is in the stage of "professional competence training-oriented" curriculum reform. Under the guidance of the major trend of personnel training objective, in vocational education, we make continuous reform and exploration for curriculum development, introduce the concept of vocational education in advanced countries, combine with practical and professional technical characteristics of our higher vocational education, propose curriculum reform study including combination of work and study and school-enterprise cooperation, and especially develop in-depth research and practice for methodology in the systematic working process of the course study field.

Reform of vocational courses has conducted fruitful research, accumulated a lot of valuable experience in the theory and practice and also achieved good results of vocational education. Some countries even achieve the fundamental purpose of vocational education. For example, ILO began developing the MES curriculum in the 1970s. The course follows the principle of "on-demand teaching consistent learning and use"; in the 1980s and 1990s, in the UK, Australia, Canada and other countries, CBE courses became popular; the competency-based curriculum adopts modular teaching 
methods; in the late 1990s, Germany had been working to develop study fields courses; the course concept follows the principle of that "vocational education should train students with complex professional competence", "curriculum design should be based on work process" and "teaching should be action-oriented". In the countries with more developed vocational education, the development of vocational courses emphasizes occupational and integrates detail of the work process into vocational courses. Vocational courses and every aspect of the work process are closely docking.

\section{Systematic work process}

At present, some fruitful researches have been made on the vocational curriculum reform, thus accumulating a large number of valuable theoretical and practical experience and achieving a good vocational education effect. Some countries fulfill the fundamental purpose of the vocational education. For example, at the 1970s, the International Labor Organization started to develop MES curriculum, and the curriculum followed the principle of "teaching according to the demand, integrating study with application”; At the 1980s and 1990s, UK, Australia, Canada and other countries started to popularize the CBE curriculum. The curriculum was based on the ability and adopted the modular teaching method; At the late 1990s, Germany has been striving to develop the curriculum at the learning field, and the curriculum concept followed the principle that "the vocational education shall cultivate students' complex professional competence", "the curriculum design shall be based on the working process" and "the teaching shall be action-oriented". In the countries with more developed vocational education, the development of the vocational curriculum stresses the professionalism, and combines the working process details into the vocational curriculum. The vocational curriculum shall be docked with each step in the working process.

The working process systemization is a kind of curriculum reform concept after the curriculum modularity and curriculum projectization, which guides the development direction of vocational curriculum reform within a longer period of time. Whether it can implement the concept for the construction and development of the own connotation of the vocational college will play a vital role, and the research on the working process systemization is the demand to adapt to the development rule of the vocational education. The curriculum concept of working process systemization needs the educators at the teaching frontline to conduct the practical interpretation and enrich the content. The manifestation of the working process systemization role will be different at various fields, industries, professions and positions, and it needs to targeted develop or reconstruct the curriculum under the guidance of the overall model of working process systemization. The frontline teachers' summary and sublimation in the practice can further improve or extend the curriculum concept of working process systemization, further enrich the education theory of the working process systemization, integrate the vocational education new concept, vocational students' professional learning feature and teaching method, conduct the systematic research on the educational policy, educational psychology, educational technology and other cross fields, conduct the in-depth practice of the vocational new concept, effectively apply the cognitive rule and educational information technology and further summarize and enrich the vocational teaching theory and teaching method. The enrich of the theory can be mainly reflected at the implementation level of the working process systemization.

In terms of the history of specific curriculum reform, the vocational curriculum reform generally experienced four stages of "modular curriculum reform", "wide-base and flexible-module curriculum reform", "project-based curriculum teaching reform" and "systematic working process curriculum reform".

To comply with the law of development of higher vocational education and improve the quality and effectiveness of vocational education, many vocational colleges have introduced the curriculum development philosophy of "work process systematization" to carry out theoretical study and exchange, reconstruct specific programs based on the work process systems and apply it to the course. Currently, under the theoretical guidance of the systematic work process and courses study field, there have been a lot of teaching materials of professional courses identified with "based on the systematic 
work process"; these materials will closely connect teaching content and skills required in the work process.

\section{C programming technology}

Currently, curriculum reform of "C programming" has made a lot of research work. " C programming" is the core course of computer science major and a professional competence course with a combination of theory and practice. In different vocational colleges, the name for the course is slightly different; it is called the " $\mathrm{C}$ language" or " $\mathrm{C}$ language programming", but the ability goals it requires to achieve and corresponding jobs are the same; combined with orientation of Dongguan Vocational and Technical College for the course, such courses are collectively referred to as "C programming" course.

"C programming" course belongs to the first batch of core courses since Dongguan Technical College was established; meantime, to meet the needs of development of the industry and the curriculum, this course changes its name several times; in 2008, it was called "Programming Theory"; in 2009, after adjustment, it was named as "Programming principles and applications"; in 2010, it was identified as the college level defined course and Vocational Computer Specialty Teaching Steering Committee of the Ministry of Education prepared the planning material "C Language Programing"; the course was adjusted to be "C Programming". As of now, " $\mathrm{C}$ Programming " course has become the specialty core course of computer professional, the first college-level project construction course and one of key construction courses of the college-level teaching team, "Computer Application Technology" team. In 2015, "Higher vocational education classroom teaching mode innovation research under the background of Internet-C Programming as an example" project has been supported by the department of education of Guangdong province. "C Programming" course is the core professional course with key construction.

\section{"C Programming" technology system remodeling ideas}

(1)curriculum development flowing the times is an eternal theme of vocational education; meanwhile, the systematic working process is a curriculum reform concept following modular curriculum and curriculum project, which will guide the development direction of curriculum reform in colleges within a longer period. The implementation of good ideas will play a crucial role for the connotation construction and development of higher vocational colleges; the study of the systematic work process is needed to meet the development law of the vocational education.

(2)In terms of curriculum development technology, the curriculum concept of systematic work process needs educators working in the front line to make practical interpretation and enrich its content. Systematic work process acting in different fields, trades, professions and jobs will have different manifestation. Under the guidance of the general model of systematic work process, we need to make targeted development or remodeling for curriculum and reconstruct the curriculum of " $\mathrm{C}$ Programming " under the guidance of systematic work process. According to curriculum development process based on the systematic working process, we need to reconstruct the course content of the traditional system and undertake curriculum reconstruction with the process of "occupational position groups - professional job skills - the skills required by professional positions (the area of action) - professional positions required knowledge (the learning field) - course learning context (including course modules, programs simulating professional positions and teaching methods and forms).

(3)In practice, based on the "design-oriented" work process systematization, curriculum development research results of " $\mathrm{C}$ Programming " in the learning field can be applied to computer science, and after the success of the pilot, it may be promoted and radiated to the school as well as other universities to benefit in a wide range. It has an important practical significance to improve the teaching quality of teachers, improve creative and practical ability of vocational students, achieve 
vocational colleges personnel's training objectives and provide a large number of skilled and high-skilled talents for social and economic development.

(4)Specific remodeling ideas include six steps.

1) Determine the typical tasks; induct action areas;

2) Converse learning areas, develop curriculum system and talent training programs;

3) Curriculum situation design and teaching standard setting of "C Programming" in learning area;

4) Learning area (courses) implementation program design and implementation of action-oriented teaching;

5) Teaching Evaluation and Feedback.

The idea's six steps as shown in Fig.1.

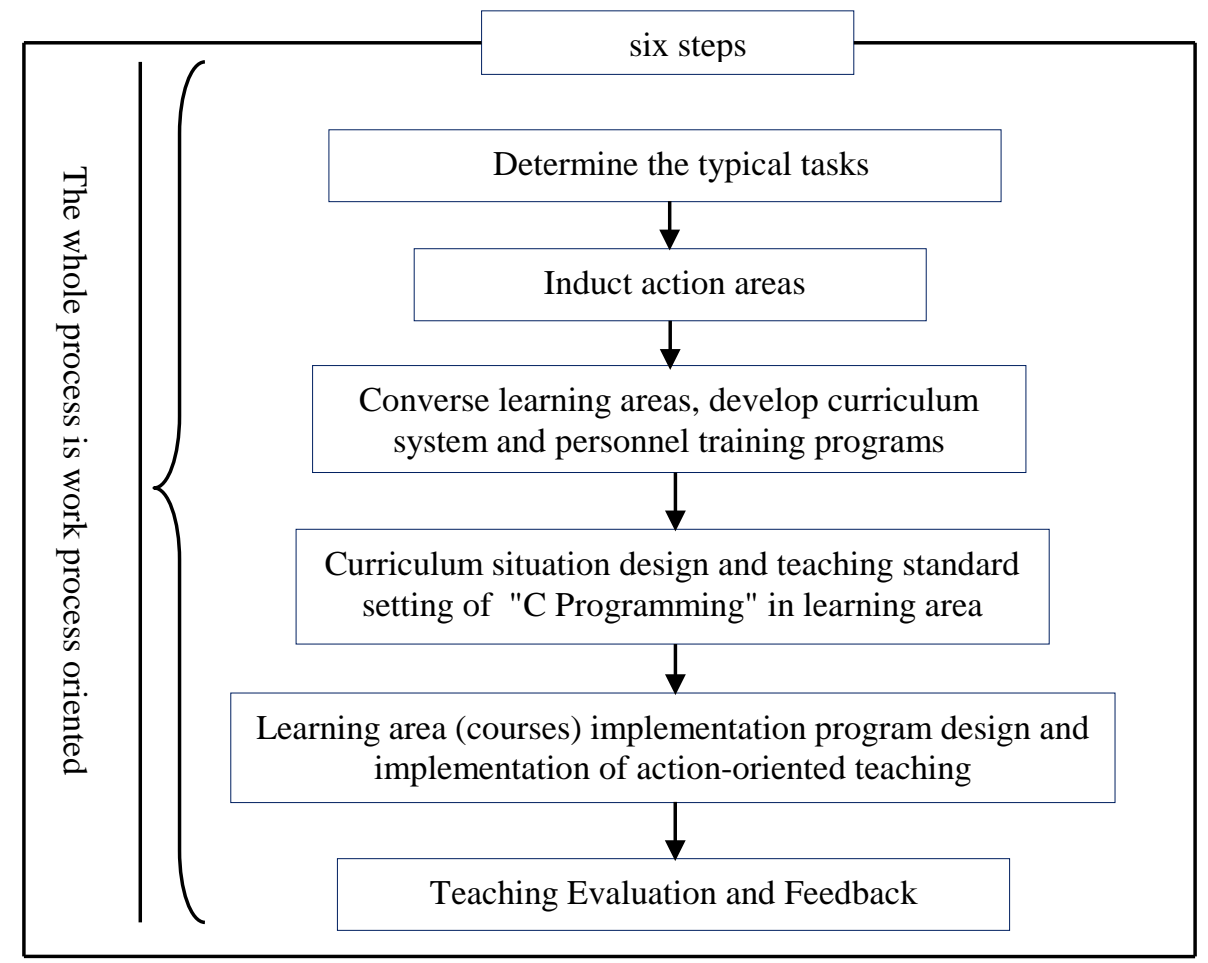

Fig.1 Six steps to reconstruct technical system

(5)Work oriented learning filed scenario development process

The process has the versatility for scenario development of course learning field and can be easily applied to other professional courses; once it's mature, it can also be promoted to other universities, it is shown in Fig.2.

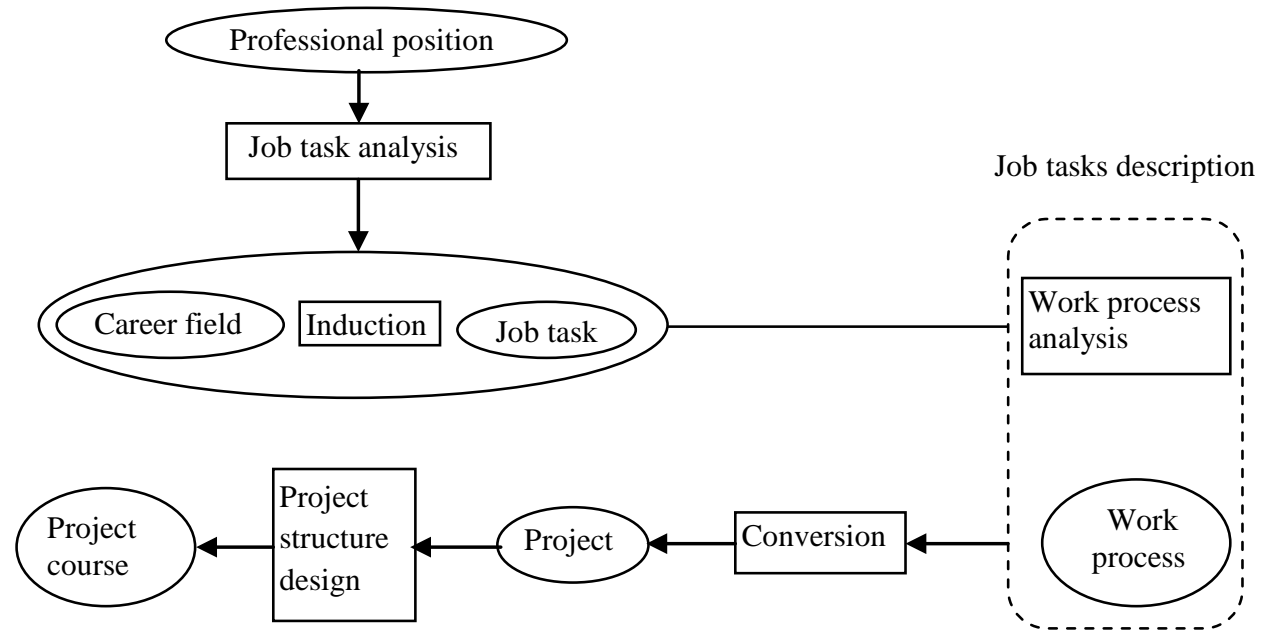

Fig.2 The development process of database technology in learning field 


\section{Scenarios building cases based on the work process}

To take database management and maintenance in the IT industry for example, vocational skills map the appropriate "C Programming" learning situation and refined teaching situations and tasks as shown in Table 1.

Table 1 A Scenario of C Programming based on the work process

\begin{tabular}{|c|c|c|c|c|c|}
\hline Responsibilities & $\begin{array}{l}\text { Work } \\
\text { content }\end{array}$ & Skills & $\begin{array}{c}\text { Knowledge (learning } \\
\text { environment) }\end{array}$ & $\begin{array}{l}\text { Study } \\
\text { hours }\end{array}$ & $\begin{array}{c}\text { Comprehensive } \\
\text { quality }\end{array}$ \\
\hline \multirow{3}{*}{$\begin{array}{l}\text { The three basic } \\
\text { structure of the } \\
\text { C language }\end{array}$} & $\begin{array}{l}\text { Sequential } \\
\text { structure }\end{array}$ & $\begin{array}{l}\text { Formatted input and } \\
\text { output; } \\
\text { Sequential structure } \\
\text { program design; } \\
\text { Character input and } \\
\text { output functions }\end{array}$ & $\begin{array}{l}\text { 1. Printf() } \\
\text { 2. Scanf() } \\
\text { 3. Expression statement } \\
\text { 4. Function call statement } \\
\text { 5. C program general structure } \\
\text { and writing rules } \\
\text { 6. Friendly user interface } \\
\text { 7. Character data input } \\
\text { 8. Character data output }\end{array}$ & 2 & \multirow{3}{*}{$\begin{array}{l}\text { Optimistic, } \\
\text { rigorous, } \\
\text { meticulous and } \\
\text { hard-working } \\
\text { spirit, } \\
\text { friendly, } \\
\text { communication } \\
\text { and teamwork } \\
\text { capability }\end{array}$} \\
\hline & $\begin{array}{l}\text { Choose } \\
\text { structure }\end{array}$ & $\begin{array}{l}\text { Based on the selection } \\
\text { problem of structure } \\
\text { design }\end{array}$ & $\begin{array}{l}\text { 1. If statement } \\
\text { 2. Switch statement } \\
\text { 3.Training of if and switch } \\
\text { statement }\end{array}$ & 2 & \\
\hline & $\begin{array}{l}\text { Loop } \\
\text { structure }\end{array}$ & $\begin{array}{l}\text { Analysis and design } \\
\text { based on the structure of } \\
\text { circulation problems }\end{array}$ & $\begin{array}{l}\text { 1. For loop statement } \\
\text { 2. While loop statement } \\
\text { 3. Do-while loop statement } \\
\text { 4. Continue statement } \\
\text { 5. Break statement } \\
\text { 6. Goto statement } \\
\text { 7. Nested loop structure } \\
\text { 8. Loop structure application } \\
\text { example }\end{array}$ & 4 & \\
\hline
\end{tabular}

\section{Conclusion}

The vocational education thought of "work process systematization" is throughout the development of the learning field of " C Programming ". It is reflected as follows: select typical learning tasks of database technology, build talent training model, determine the typical tasks of "C Programming" learning areas and make use of the complete work process as the learning situation; pay more attention to students' ability to design in curriculum standards development process; in the action-oriented teaching, make students actively participate in the planning and implementation; learn to solve problems and demonstrated techniques; complete tasks in a given design space; in teaching evaluation and feedback, allow students to participate in the formulation of evaluation programs and evaluate the work process and outcome; teachers carefully study the student feedback and make timely adjustment and correction of teaching process in order to better promote the implementation and correction of the action-oriented teaching. From the perspective of "work process oriented" vocational education, the paper makes system development of "C Programming in the learning area. While training students' professional skills, it pays more emphasis on training students to analyze problems, design solutions and innovative problem-solving skills, so as to promote the development of students' "design capacity" and achieve strategic change of vocational education from the "adaptation-oriented" nature to "design-oriented" nature. 


\section{Acknowledgements}

This work was financially supported by the project of Guangdong Province education technology teaching reform (No.2015021, No.2015089, No.2015019), and by the key teaching reform project of Dongguan Polytechnic in 2016 - "Polytechnic teaching quality evaluation model based on decision tree", and by the Dongguan philosophy and social sciences planning project in 2016 (No.2016JY04), and by the project of higher vocational education teaching reform in Guangdong province"Computer Application Basis course flip classroom research and practice based on the MOOC and WeiChat APP".

\section{References}

[1]NING Chen, LIU Yaqin. Research on Design of distance Teaching Resources Based on Working Process. Vocational and Technical Education, 11, pp.62-65, 2013.

[2]Jiang Wuxue, Hu Xuanzi, Gao Weichun, Li Mingchao. Design and Optimization of Java Technology Module based on Working Process Systemization. Advanced Materials Research, 850-851, pp.709-713, 2014.

[3]SHEN Rongwei, TAI Xiaohong, HUANG Bingyi. Research on Integration Practice and Theories Curriculum Development Method Based on Working Process and Action-oriented. Vocational and Technical Educatio, 29, pp.25-27, 2013.

[4]HU Wanyu. Analysis on the Characteristics of Development and Implementation of Working Process-oriented Courses in Higher Vocational Education. Vocational and Technical Education, 2, pp.53-54, 2013.

[5]Jiang Wu Xue, Hu Xuan Zi, Gao Wei Chun, Ye Guang Zai. Reconstruction on database technology module based on university-enterprise cooperation for polytechnic. Advanced Materials Research, 926-930, pp.1203-1206, 2014.

[6]Chih-Hsuan Wang, Juite Wang. Combining fuzzy AHP and fuzzy Kano to optimize product varieties for smart cameras: A zero-one integer programming perspective. Applied Soft Computing, 22, pp.410-416,2014.

[7]Williamson Ben. New governing experts in education: Self-learning software, policy labs and transactional pedagogies. School of Education Book Chapters and Sections, 55, pp.218-231,2014.

[8]Jiang Wuxue, Chai Pei, Chen Yuqiang, Wang Shi. University-enterprise Cooperation Practical Teaching Evaluation Model for polytechnic based on AHP and Fuzzy. Advances in Computer Science Research, 17, pp.282-285, 2015.

[9]JosePh Sterling Mattoon. Designing and Deve1oPing Technical Curricu1u. Finding the Right Subject Matter ExPert, 42, pp.375-404, 2005.

[10]Rai Arun, Hornyak. The impact of sourcing enterprise system use and work process interdependence on sourcing professionals' job outcomes. Journal of Operations Management, 31(6), pp. 474-488, 2013.

[11]Jiang Wu Xue, Zhong Yin Zhen, Liang Huan. An evaluation model of polytechnic teaching quality based on ID3 decision making tree. Applied Mechanics and Materials, 651-653, pp.2437-2440, 2014.

[12]HUA Xiang-juan. Strategy of Curriculum Development for Teachers and Enterprises to Participate in College-enterprise Cooperation Together. JOURNAL OF LIAONING HIGHER VOCATIONAL, 14, pp.61-94, 2012. 